\title{
Race, Socioeconomic Status, and Sex Hormones among Male and Female American Adolescents
}

\author{
Shervin Assari ${ }^{1, * \mathbb{C}}$, Shanika Boyce ${ }^{2}$, Mohsen Bazargan ${ }^{1,3}$ and Cleopatra H. Caldwell ${ }^{4}$ \\ 1 Department of Family Medicine, Charles Drew University, Los Angeles, CA 90059, USA; \\ mohsenbazargan@cdrewu.edu \\ 2 Department of Pediatrics, Charles Drew University, Los Angeles, CA 90059, USA; shanikaboyce@cdrewu.edu \\ 3 Department of Family Medicine, University of California Los Angeles (UCLA), Los Angeles, CA 90095, USA \\ 4 Department of Health Behavior and Health Education, University of Michigan, Ann Arbor, MI 48109, USA; \\ cleoc@umich.edu \\ * Correspondence: assari@umich.edu; Tel.: +1-734-858-8333
}

Received: 7 July 2020; Accepted: 30 July 2020; Published: 3 August 2020

check for updates

\begin{abstract}
Although early sexual initiation and childbearing are major barriers against the upward social mobility of American adolescents, particularly those who belong to a low socioeconomic status (SES) and racial minorities such as Blacks, less is known on how SES and race correlate with adolescents' sex hormones. An understanding of the associations between race and SES with adolescents' sex hormones may help better understand why racial, and SES gaps exist in sexual risk behaviors and teen pregnancies. To extend the existing knowledge on social patterning of adolescents' sex hormones, in the current study, we studied social patterning of sex hormones in a national sample of male and female American adolescents, with a particular interest in the role of race and SES. For this cross-sectional study, data came from the baseline data (wave 1) of the Adolescent Brain Cognitive Development (ABCD) study, a national longitudinal prospective study of American adolescents. This analysis included 717 male and 576 female non-Hispanic White or Black adolescents ages 9-10. The dependent variables were sex hormones (testosterone for males and estradiol for females). Independent variables were age, race, family marital status, parental education, and financial difficulties. For data analysis, linear regression models were used. Age, race, parental education, and financial difficulties were associated with estradiol in female and testosterone levels in male adolescents. Associations were not identical for males and females, but the patterns were mainly similar. Low SES explained why race is associated with higher estradiol in female adolescents. Marital status of the family did not correlate with any of the sex hormones. Being Black and low SES were associated with a higher level of sex hormones in male and female adolescents. This information may help us understand the social patterning of sexual initiation and childbearing. Addressing racial and economic inequalities in early puberty, sexual initiation, and childbearing is an essential part of closing the racial and economic gaps in the US.
\end{abstract}

Keywords: population groups; ethnic groups; puberty; education; maternal age; childbirth

\section{Introduction}

High levels of sex hormones in early adolescents are linked to early puberty, which itself is a predictor of sexual initiation, early childbearing, and teen pregnancy [1]. The significance of early puberty and early sexual initiation is very high because it is linked to teen pregnancy [1]. As such, an understanding of the social patterning of baseline status, as well as the growth of sex hormones in adolescents, is essential because it may expose the adolescents to an increased risk of early parenting and early childbearing, which are known risk factors contributing to poor health and a lack of economic 
wellbeing [2]. As such, any epidemiological studies on sex hormones can inform us about the social patterning of sexual initiation, which may help us prevent inequalities in early pregnancy [3] and associated consequences $[1,4,5]$.

Prevention of early sexual initiation would reduce maternal mortality [6], perinatal depression [7], and poor parenting $[5,8,9]$, as well as unstable interpersonal relationships $[5,8,9]$. As there are several undesired consequences of early sexual initiation $[10,11]$, and given that information may be helpful to prevent teen pregnancy through delaying sex [11,12], there is a need to conduct more studies on the socioeconomic precursors of two important correlates of early sexual initiation and sex hormones [13].

In the United States, race and SES are major correlates of sexual initiation, early childbearing, and teen pregnancy $[14,15]$. In the US, relative to their White counterparts, Black adolescents are at an increased risk of early puberty, sexual initiation, and teen pregnancy $[14,15]$. At the same time, early puberty and teen pregnancy are more common in sections of society dealing with socioeconomic disadvantage [16]. Early puberty and teen pregnancy also operate as a barrier against upward social mobility $[17,18]$. As such, low SES is both a precursor and a consequence of early puberty, sexual initiation, and childbearing [5,19]. Teen pregnancy, partially rooted in early puberty, combined with a lack of resources in neighborhoods, can become a recipe for what is known as a poverty trap $[18,20]$ and a loss of the ability to move up from the low to the middle class (upward social mobility) [17,18]. While early pregnancy is detrimental to both males and females, the adverse effects of teen pregnancy as a barrier against upward social mobility is more pronounced for girls than boys [16]. In other terms, early puberty, and associated sexual and reproductive behaviors may be a mechanism by which low SES and poverty are repeated across generations [17,18].

Recent studies have shown that although there are associations between SES (poverty) and early sexual initiation and age of childbirth [16], this social patterning may be more relevant to Whites than Blacks. This may be because the gain in postponing sexual initiation may be more diminished for Blacks than for Whites [21]. In other terms, Black individuals may be at risk of early childbearing and teen pregnancy regardless of their SES, while for White females, as SES increases, their childbearing is delayed [16]. This may also be why parental education generates more upward social mobility for White than for Black adolescents [22,23].

As race and SES overlap [24], there is a need to conduct studies that investigate the joint effects of race and SES on determinants of sex hormones [21,25], as precursors of early childbearing [26]. In theory, SES may partially explain some of the inequalities between Whites and Blacks in the United States. Some research has also listed that early puberty, sexual initiation, and pregnancy may be one of the mechanisms that form a poverty trap for Black women $[20,27,28]$. Females will face additional difficulties in climbing the social ladder and moving from a low- to a middle-class status if they engage in early sexual initiation $[29,30]$. This is mainly because women would need to spend considerable time and energy on maternity rather than their own social mobility $[29,30]$. Thus, understanding how race and SES jointly shape social inequalities in early puberty, sexual initiation and teen pregnancy remain essential as a strategic goal [31-33]. Other than a few numbers [21,25], we are not aware of any other studies on the combined effects of race and SES on sex hormones, predicting both sexual initiation and early pregnancy. Thus, there is a need to conduct more studies that explore the additive effects of race and SES on adolescents' sex hormones as a correlate of early puberty, sexual initiation, and teen pregnancy in the US.

\section{Objectives}

The present study explored the social patterning of sex hormones in male and female American adolescents. We studied how SES indicators, namely parental education, financial difficulties, marital status, and race, correlate with sex hormones (testosterone for males and estradiol for females) in adolescents. In this study, we conceptualized sex hormones as strong predictors of early sexual maturation, sexual debut, and early childbearing for male and female adolescents $[1,20,34-36]$. 
We used a national sample of male and female White and Black adolescents who had participated in the Adolescent Brain Cognitive Development (ABCD) [37-45].

\section{Materials and Methods}

\subsection{Design and Settings}

This is a secondary analysis of the ABCD study. We performed a cross-sectional analysis of the $\mathrm{ABCD}$ data. $\mathrm{ABCD}$ is a national, state-of-the-art brain imaging study of adolescents' brain development [37-45].

\subsection{Advantage of the $A B C D$ Study}

Among the main advantages of the ABCD data set are (1) a national sample, (2) a large sample size, (3) a large sample of Blacks, (4) a multiple robust measures of brain measures, (5) a wide range of behavioral measures, and (6) considerable socioeconomic and environmental and psychological variables [37-45]. This study included 717 male and 576 female adolescents who were all non-Hispanic and were either Black or White.

\subsection{Study Variables}

\subsubsection{Dependent Variables}

Sex Hormones. Salimetric hormone tests were performed for estradiol (females) and testosterone (males). These variables were presented as mean of measures $(\mathrm{pg} / \mathrm{mL})$ and were treated as continuous measures.

\subsubsection{Independent Variables}

Race. In the ABCD study, race was measured as self-identified. Race in the current study was a dichotomous variable (Blacks $=1$, Whites $=0$ ).

Age. Parents reported the age of adolescents. Age was a continuous variable, measured in months.

Family marital status. Family marital status, a dichotomous variable, was self-reported by the interviewed parent.

Parental Educational Attainment. Participants were asked, "What is the highest grade or level of school you have completed or the highest degree you have received?" Responses were 0 for any of the following answers: Never attended/Kindergarten only; 1st-12th grade, and 1 for high school graduate; GED or equivalent Diploma; some college education; and any college degree. This variable was treated as a continuous measure with 1 , indicating the lowest and 21 indicating the highest educational attainment.

Financial Stress. Financial difficulties were measured using the following seven items. Participants were asked "In the past 12 months, has there been a time when you and your immediate family experienced any of the following:" (1) "Needed food but couldn't afford to buy it or couldn't afford to go out to get it?", (2) "Were without telephone service because you could not afford it?" (3) "Didn't pay the full amount of the rent or mortgage because you could not afford it?", (4) "Were evicted from your home for not paying the rent or mortgage?", (5) "Had services turned off by the gas or electric company, or the oil company wouldn't deliver oil because payments were not made?", (6) "Had someone who needed to see a doctor or go to the hospital but didn't go because you could not afford it?" and (7) "Had someone who needed a dentist but couldn't go because you could not afford it?". Responses to each item was 0 or 1 . We calculated a mean score (a continuous measure), which ranged between 0 and 1, with higher scores indicating higher levels of financial stress. Financial stress is an accepted SES indicator, as it reflects some aspects of the SES which are not captured by objective SES indicators such as education, income, and employment [46-52]. Financial stress and other aspects of subjective SES are shown to have some health effects that are not seen by objective SES indicators $[46,48,49,53-55]$. 


\subsubsection{Moderator}

Sex. Sex was a dichotomous variable. This variable was not included as a variable to the models. Instead, we ran sex-stratified models.

\subsection{Data Analysis}

SPSS 22.0 statistical package was used to perform our data analysis. Frequency (\%) and mean (standard deviation; SD) of our variables were reported for the description of the data. To perform our multivariable analyses, we performed two linear regressions, one for males with testosterone as the outcome, and one for females with estradiol as the outcome. As the first step, we tested the normal distribution of our outcome. We also tested the random distribution of errors for our linear regression model. We also ruled out collinearity between our predictors. The dependent variable was a sex hormone, and independent variables were race, age, family marital status, parental education, and financial difficulties. Our first model only included age and race. Then we controlled for SES indicators. This approach could inform us if racial variation in sex hormones is due to an SES gap between Black and White adolescents. As models were run specific to sex, sex was not included in the models (sex was used to determine the strata). We did not run logistic regression for several reasons. First, our SES indicators, such as parental education and financial distress, were continuous measures. Our outcomes were also continuous measures without any known threshold that can be applied. Besides, most of the existing literature on the determinants of sex hormones have applied linear regression models to model the variation in the outcome [56-60]. The decision to use linear regression was also based on the fact that [61-63] mediational models are easier to operationalize when the mediators and the outcomes are continuous measures. Unstandardized regression coefficient (b), SE, 95\% Confidence Interval (CI), and $p$-value are reported.

\subsection{Ethical Aspect}

The ABCD study protocol is approved by the University of California, San Diego (UCSD) Institutional Review Board (IRB). All adolescent participants gave assent. Parents signed informed consent. More detailed information on the ABCD study ethics is available elsewhere [55]. As we used fully de-identified data, our study was non-human subject research. Thus, it was exempted from a full review.

\section{Results}

The current analysis was performed on 717 male 576 female nine to ten years old adolescents who were either non-Hispanic White (75.7\% for males and 70.0\% for females) or non-Hispanic Black (24.3\% for males and $30.0 \%$ for females). Table 1 presents descriptive statistics of the pooled sample.

Table 1. Descriptive statistics by sex.

\begin{tabular}{ccccc}
\hline & \multicolumn{2}{c}{ Males } & \multicolumn{2}{c}{ Females } \\
\cline { 2 - 5 } & $\boldsymbol{n}$ & $\%$ & $\boldsymbol{n}$ & $\mathbf{\%}$ \\
\hline Race & & & 403 & 70.0 \\
Non-Hispanic White & 543 & 75.7 & 173 & 30.0 \\
Non-Hispanic Black & 174 & 24.3 & 576 & 100.0 \\
Sex & & & - & - \\
Female & - & 100.0 & 190 & 33.0 \\
Male & 717 & & 386 & 67.0 \\
Family Marital Status & 219 & 30.5 & 69.5 &
\end{tabular}


Table 1. Cont.

\begin{tabular}{ccccc}
\hline & \multicolumn{2}{c}{ Males } & \multicolumn{2}{c}{ Females } \\
\cline { 2 - 5 } & $\boldsymbol{n}$ & \% & $\boldsymbol{n}$ & Mean \\
\hline & Mean & SD & 118.14 & 7.32 \\
Age (Months) & 119.14 & 7.42 & 16.73 & 2.42 \\
Parental Education (1-21) & 16.81 & 2.31 & 0.62 & 1.34 \\
Financial Stress (0-1) & 0.46 & 1.08 & - & - \\
Testosterone (pg/mL) & 36.71 & 19.40 & 39.09 & 20.42 \\
Estradiol (pg/mL) & - & - & & \\
\hline
\end{tabular}

SF: Standard deviation.

Table 2 indicates the findings of two linear regression models in males with testosterone as the dependent variable. Model 1 showed that race $(b=0.16, p<0.001)$ and age $(b=0.13, p=0.001)$ are associated with testosterone levels, when SES is not controlled. However, when SES is controlled, race was only marginally associated with higher testosterone $(b=0.08, p=0.067)$. In this model, financial strain was associated with an increased, and parental education was associated with a reduced, testosterone level.

Table 3 indicates the findings of two linear regression models in females with estradiol as the dependent variable. The first model showed that age $(b=0.15, p<0.001)$ and race $(b=0.16, p<0.001)$ were associated with estradiol levels. The second model shows that race $(b=0.18, p<0.001)$ remains associated with higher estradiol when SES is controlled. Besides, age, financial strain, and parental education were associated with estradiol levels. Financial strain was associated with increased, and parenteral education was associated with reduced, estradiol. 
Table 2. Regression models in boys (testosterone).

\begin{tabular}{|c|c|c|c|c|c|c|c|c|c|c|c|c|c|c|}
\hline & \multicolumn{7}{|c|}{ Model 1: Did not Adjust for SES } & \multicolumn{7}{|c|}{ Model 2: Adjusted for SES } \\
\hline & Beta & $b$ & $S E$ & 95 & & $\mathbf{t}$ & $p$ & Beta & $b$ & $S E$ & $95^{\circ}$ & & $\mathbf{t}$ & $p$ \\
\hline Age & 0.13 & 0.33 & 0.10 & 0.15 & 0.52 & 3.49 & 0.001 & 0.13 & 0.33 & 0.09 & 0.15 & 0.52 & 3.52 & $<0.001$ \\
\hline Race (Black) & 0.16 & 7.45 & 1.66 & 4.20 & 10.70 & 4.50 & $<0.001$ & 0.08 & 3.61 & 1.97 & -0.26 & 7.48 & 1.83 & 0.067 \\
\hline Parents Married & - & - & - & - & - & - & - & -0.04 & -1.58 & 1.83 & -5.17 & 2.00 & -0.87 & 0.387 \\
\hline Parental Education & - & - & - & - & - & - & - & -0.12 & -1.01 & 0.34 & -1.68 & -0.33 & -2.94 & 0.003 \\
\hline Financial Strain & - & - & - & - & - & - & - & 0.09 & 1.57 & 0.69 & 0.22 & 2.92 & 2.29 & 0.022 \\
\hline Intercept & & -4.92 & 11.46 & -27.41 & 17.58 & -0.43 & 0.668 & & 13.48 & 12.87 & -11.78 & 38.74 & 1.05 & 0.295 \\
\hline
\end{tabular}

SES: Socioeconomic status; SE: Standard Error; CI: Confidence Interval.

Table 3. Regression models in girls (outcome = estradiol)

\begin{tabular}{|c|c|c|c|c|c|c|c|c|c|c|c|c|c|c|}
\hline \multirow[b]{3}{*}{ Age } & \multicolumn{7}{|c|}{ Model 1: Did not Adjust for SES } & \multicolumn{7}{|c|}{ Model 2: Adjusted for SES } \\
\hline & \multirow{2}{*}{$\begin{array}{c}\text { Beta } \\
0.15\end{array}$} & \multirow{2}{*}{$\begin{array}{c}\boldsymbol{b} \\
0.01\end{array}$} & \multirow{2}{*}{$\begin{array}{c}S E \\
0.00\end{array}$} & \multicolumn{2}{|c|}{$95 \% C I$} & \multirow{2}{*}{$\begin{array}{c}\mathbf{t} \\
3.62\end{array}$} & \multirow{2}{*}{$\begin{array}{c}p \\
<0.001\end{array}$} & \multirow{2}{*}{$\begin{array}{c}\text { Beta } \\
0.15\end{array}$} & \multirow{2}{*}{$\begin{array}{c}\boldsymbol{b} \\
0.01\end{array}$} & \multirow{2}{*}{$\begin{array}{c}S E \\
0.00\end{array}$} & \multicolumn{2}{|c|}{$95 \% C I$} & \multirow{2}{*}{$\begin{array}{c}\mathbf{t} \\
3.75\end{array}$} & \multirow{2}{*}{$\begin{array}{c}p \\
<0.001\end{array}$} \\
\hline & & & & 0.00 & 0.02 & & & & & & 0.01 & 0.02 & & \\
\hline Race (Black) & 0.16 & 0.18 & 0.05 & 0.09 & 0.28 & 3.81 & $<0.001$ & 0.18 & 0.21 & 0.06 & 0.10 & 0.33 & 3.58 & $<0.001$ \\
\hline Parents Married & - & - & - & - & - & - & - & 0.01 & 0.01 & 0.06 & -0.10 & 0.12 & 0.22 & 0.827 \\
\hline Parental Education & - & - & - & - & - & - & - & 0.10 & 0.02 & 0.01 & 0.00 & 0.04 & 2.20 & 0.028 \\
\hline Financial Strain & - & - & - & - & - & - & - & 0.09 & 0.03 & 0.02 & 0.00 & 0.07 & 1.98 & 0.048 \\
\hline Intercept & & -0.26 & 0.35 & -0.95 & 0.44 & -0.72 & 0.469 & & -0.73 & 0.41 & -1.53 & 0.07 & -1.80 & 0.073 \\
\hline
\end{tabular}

SES: Socioeconomic status; SE: Standard Error; CI: Confidence Interval. 


\section{Discussion}

In a national sample of 9-10-year-old American adolescents, race and SES (parental education and financial stress) were associated with the testosterone of male and the estradiol of female adolescents. Neither in males nor in females was having married parents associated with sex hormones. At least for testosterone, some of the effects of race on sex hormones was due to SES. SES, however, did not explain racial differences in the estradiol levels of female adolescents.

Studies have shown that high SES delays the timing of puberty $[20,27,28,34-36,64]$. More specifically, having highly educated parents may delay the timing of puberty [25]. We found that high SES measured as parental education and low financial difficulties are associated with lower levels of sex hormones in American adolescents, effects that are independent of the effect of race. This means that sex hormones are associated with race and SES, however, in a complicated way. It means that the role of race and SES on shaping sex hormones depends on sex (sex hormone), and SES indicators. Moreover, marital status of the family did not correlate with testosterone or estradiol, while financial difficulties and parental education did correlate with testosterone and estradiol.

These results are of interest because they inform us about why and how SES and race correlate with early puberty, sexual maturation, sexual activity, and early pregnancy. These all may tend to be more common and earlier for low SES and Black adolescents, thus parental education and financial distress may enable us to help high-risk kids to delay their pregnancy risk. In our study, marital status may not correlate with sex hormones.

The results are also relevant to the literature that suggests that girls' education has a major effect on improving the SES, and an increase in the age of delivery of a first child would have a large effect on the upward social mobility of girls $[20,27,34,65]$. Brookings Institution has listed delay in pregnancy to adulthood, education, and employment as the three necessary activities for upward social mobility $[17,18]$. Educational campaigns and sex education programs that educate male and female youth may contribute to their social mobility by preventing teen pregnancy [66,67].

As race and SES have additive effects, Black adolescents from a lower SES background may experience two types of jeopardies. For Whites, delayed puberty provides an opportunity for upward social mobility. For Black and low SES adolescents, however, the risk of early pregnancy may be high because their sex hormones are high. Given that early sexual maturation and puberty are close correlates of early sexual risk-taking, sexual initiation, and childbearing, programs and interventions should help low SES and Black communities abstain or practice safe sex that does not result in teen pregnancy. Youths who are Black or from a low SES background are more likely to live in urban communities affected by structural inequalities, limited resources, and blocked opportunities. In these neighborhoods, scarcity of resources is associated with dense crime and poverty, as well as with high levels of stress, environmental toxins, and risk [68-78]. As a proxy of experiencing such disadvantages, and as a proxy of living in such contexts, SES and race [32] show an association with the timing of puberty, sexual initiation, and childbearing $[16,21]$. However, more research is needed to support this position.

\subsection{Implications}

These results may have implications for clinical practice or even policy and public health, particularly for sex education. It is essential to design, implement, and evaluate interventions and programs that increase sexual literacy and reduce sexual risk and associated early pregnancy for low SES and Black adolescents. There is a need for multilevel public and economic policy solutions that may help adolescents make informed sexual decisions, to abstain from sex, delay sex, or have protected sex, so they can avoid early pregnancy. As a result of these programs, adolescents can focus on their education and upward social mobility, without being distracted by teen pregnancy, which means they should take responsibility for the upbringing of another child while themselves are still children. It is important to notice that these interventions are needed everywhere. However, they may be of particular importance in low SES and Black communities. Addressing health inequalities should go 
beyond equalizing SES. Similarly, there is a need to reduce teen pregnancies in the lives of minorities. Such efforts may be a major part of the efforts to promote equality across racial and ethnic groups. To remove the persistence of racial and economic health disparities in the US, policies should directly target the social stratification, racism, segregation, and discrimination. Such multilevel interventions should jointly consider race and SES as these social determinants shape distribution of risk in the US.

Our study was on sex hormones, which are correlates of puberty, sexual initiation, and early pregnancy in adolescents. Gathering more epidemiological data on early sex and teen pregnancy is one reason we conducted this study on sex hormones, which are correlated with early puberty and associated sexual risk [79-81]. As early puberty results in early sexual initiation and teen pregnancy [82], it becomes a risk factor for a wide range of outcomes such as low income, welfare dependency, fewer job opportunities, and low living standards [83]. To get involved in early parenting, adolescents would be required to leave their education or job and spend time on maternity and parenting [84]. As a result, many young individuals who become parents as a child may experience a gap in their participation in the education and labor market [84]. They may also experience additional difficulties with marriage and intimate relations with their own parents [8]. As a result of early pregnancy, women may experience higher levels of stress, interpersonal conflict, and interruption in their work. All these factors may reduce the economic return for mothers, particularly teen moms [85]. They may also have fewer opportunities when they return to the labor market. The labor market may also return their effort with lower pay. They may also be faced with various levels of adversities, constraints, and frictions in their search for upward educational and occupational mobility [84]. As a result, teenage moms face additional barriers against their upward social mobility, at least for several years, which has considerable implications on their economic and human development as well as their financial wellbeing [83].

\subsection{Future Research}

We should study the potential causative pathways that may explain why race and SES are linked to sex hormones. It is quite likely that stress (due to lower SES) [86], poor diet [87], lack of an intellectually stimulating environment [88], and even toxins increase the level of sexual hormones. It is important to test the mediational effects of these factors. There is also a need to address whether social security can undo these paths. Various SES indicators such as parental educational attainment and poverty status may have differential effects on sex hormones of boys and girls. As SES impacts sex hormones, which in turn influences adolescents' engagement in sexual activity, there is a need to study how reproduction operates as a barrier against upward social mobility for boys and girls from low SES families. This means that there is a need to study whether diminished returns of family SES also reduce the chance of boys' and girls' success through increasing their chance of investing in their upward social mobility and building human capital without getting involved in teen pregnancy.

\subsection{Limitations}

This study has several limitations. First, the association reported here is not causal. The association between race, SES, and sex hormones may be confounded by many unmeasured factors not included in this study. We also did not study the timing of puberty and childbearing. Genetics, nutrition, behaviors such as sleep, exercise, physical activity, and many other factors may influence sex hormones. This study measured some but not all SES indicators. We also did not have twin data that match in some environmental factors and even genetic and biological factors. Repeated measures and trajectories of SES and sex hormones may provide more detailed information than a cross-sectional snapshot of the link between SES and sex hormones. Structural factors such as racial and ethnic composition, the density of resources, concentration of poverty, and environmental exposures may be among factors that impact sex hormones and sexual maturation. Future research should collect data on these factors. Despite all these limitations, this is one of the first studies on the additive effects of race and SES on 
sex hormones. Another strength was using a national sample, a significant overall sample size, and a relatively large sub-sample of Black adolescents.

\subsection{Policy and Program Implications}

There are some successful policies where educational campaigns [89], mentorships [90], and empowerment [91] and resilience [92] of girls and boys have improved the SES and increased the age of delivery of the first child. In addition, multilevel interventions may generate some hope [93]. Faith-based programs may also have some positive impact. Furthermore, parenting programs may have some effects [94,95]. The ecological approach and upstream interventions that reduce financial difficulties and help improve families' SES may be most effective [96]. Similarly, there is some evidence suggesting that these programs may have some spillover effects, so targeting better sexual decisions may also affect other behaviors such as drug use, and even health [97]. More research is needed to help us select the available public health action measures that we can take, which would be most relevant to improving these inequal situations.

\section{Conclusions}

Race and SES are jointly correlated with sex hormones in adolescents. How race and SES correlate with sex hormones are not identical for estradiol and testosterone in females and males. Family marital status did not show an association with testosterone in male adolescents or estradiol in female adolescents. However, parental education and financial strain do correlate with sex hormones for male and female adolescents. Social patterning of sex hormones may contribute to the social patterning of early sexual maturation, early puberty, sexual initiation, childbearing, and teen pregnancy. This information may help reduce SES and racial inequalities in youth sexual behaviors and associated outcomes.

Author Contributions: S.A. conceptual design, first draft, revision, approval: S.B., C.H.C., M.B.: Conceptual design, revision, and approval. All authors have read and agreed to the published version of the manuscript.

Funding: Shervin Assari is supported by the National Institutes of Health (NIH) grants CA201415-02, 5S21MD000103, D084526-03, CA201415-02, DA035811-05, U54MD008149, U54MD007598, U54CA229974, and U54CA229974.

Conflicts of Interest: The authors declare no conflict of interest. The funders had no role in the design of the study; in the collection, analyses, or interpretation of data; in the writing of the manuscript, or in the decision to publish the results.

\section{References}

1. Carter, D.M.; Felice, M.E.; Rosoff, J.; Zabin, L.S.; Beilenson, P.L.; Dannenberg, A.L. When children have children: The teen pregnancy predicament. Am. J. Prev. Med. 1994, 10, 108-113. [CrossRef]

2. Saloojee, H.; Coovadia, H. Maternal age matters: For a lifetime, or longer. Lancet Glob. Health 2015, 3, e342-e343. [CrossRef]

3. Lin, C.J.; Nowalk, M.P.; Ncube, C.N.; Aaraj, Y.A.; Warshel, M.; South-Paul, J.E. Long-term Outcomes for Teen Mothers Who Participated in a Mentoring Program to Prevent Repeat Teen Pregnancy. J. Natl. Med. Assoc. 2019, 111, 296-301. [CrossRef]

4. Kirby, D. Reflections on two decades of research on teen sexual behavior and pregnancy. J. Sch. Health 1999, 69, 89-94. [CrossRef] [PubMed]

5. Bell, C.A.; Casto, G.; Daniels, D.S. Ameliorating the impact of teen-age pregnancy on parent and child. Child Welfare 1983, 62, 167-173. [PubMed]

6. Schellpfeffer, M.A.; Gillespie, K.H.; Rohan, A.M.; Blackwell, S.P. A Review of Pregnancy-Related Maternal Mortality in Wisconsin, 2006. WMJ 2015, 114, 202-207. 
7. Koleva, H.; Stuart, S. Risk factors for depressive symptoms in adolescent pregnancy in a late-teen subsample. Arch. Womens Ment. Health 2014, 17, 155-158. [CrossRef]

8. Denny, T.; Jahromi, L.B.; Zeiders, K.H. Incongruent Teen Pregnancy Attitudes, Coparenting Conflict, and Support Among Mexican-Origin Adolescent Mothers. J. Marriage Fam. 2016, 78, 531-545. [CrossRef]

9. Okwumabua, T.M.; Okwumabua, J.O.; Elliott, V. "Let the Circle be Unbroken" helps African-Americans prevent teen pregnancy. SIECUS Rep. 1998, 26, 12-17.

10. Bogan, D.R.; Aranmolate, R.; Mawson, A.R. Confronting the impact of teen pregnancy in Mississippi: The need for after-school programs. Int. J. Adolesc. Med. Health 2019. [CrossRef]

11. Marseille, E.; Mirzazadeh, A.; Biggs, M.A.; Amanda, P.M.; Horvath, H.; Lightfoot, M.; Malekinejad, M.; Kahn, J.G. Effectiveness of School-Based Teen Pregnancy Prevention Programs in the USA: A Systematic Review and Meta-Analysis. Prev. Sci. 2018, 19, 468-489. [CrossRef] [PubMed]

12. Goesling, B.; Colman, S.; Trenholm, C.; Terzian, M.; Moore, K. Programs to reduce teen pregnancy, sexually transmitted infections, and associated sexual risk behaviors: A systematic review. J. Adolesc. Health 2014, 54, 499-507. [CrossRef] [PubMed]

13. Udry, J.R. Hormonal and social determinants of adolescent sexual initiation. Adolesc. Puberty 1990, 3, 70-87.

14. Barr, A.B.; Simons, R.L.; Simons, L.G.; Gibbons, F.X.; Gerrard, M. Teen motherhood and pregnancy prototypes: The role of social context in changing young African American mothers' risk images and contraceptive expectations. J. Youth Adolesc. 2013, 42, 1884-1897. [CrossRef]

15. Waddell, E.N.; Orr, M.G.; Sackoff, J.; Santelli, J.S. Pregnancy risk among black, white, and Hispanic teen girls in New York City public schools. J. Urban Health 2010, 87, 426-439. [CrossRef]

16. Raymo, J.M.; Carlson, M.J.; VanOrman, A.; Lim, S.-j.; Perelli-Harris, B.; Iwasawa, M. Educational differences in early childbearing: A cross-national comparative study. Demogr. Res. 2015, 33, 65. [CrossRef]

17. Sawhill, I.V. What Can Be Done to Reduce Teen Pregnancy and Out-of-Wedlock Births; Welfare Reform \& Beyond Initiative, Brookings Institution: Washington, DC, USA, 2001; Volume 8.

18. Haskins, R. Three simple rules poor teens should follow to join the middle class. Available online: https://www. brookings.edu/opinions/three-simple-rules-poor-teens-should-follow-to-join-the-middle-class/ (accessed on 30 July 2020).

19. Cygan, H.R.; McNaughton, D.; Reising, V.; Fogg, L.; Marshall, B.; Simon, J. Teen pregnancy in Chicago: Who is at risk? Public Health Nurs. 2020, 37, 353-362. [CrossRef]

20. Young, T.M.; Martin, S.S.; Young, M.E.; Ting, L. Internal poverty and teen pregnancy. Adolescence 2001, 36, 289-304.

21. Assari, S.; Mardani, A.; Maleki, M.; Bazargan, M. Black-White Differences in the Association between Maternal Age at Childbirth and Income. Women's Health Bull. 2019, 6, 36-42.

22. Dobbins, C.C.; Kenney, B.N.; Meier, C.E.; Taormina, V.V. Down With Teen Pregnancy, Up With Mobility: Teen Pregnancy Prevention Efforts in Gaston County, North Carolina. N. Carol. Med. J. 2016, 77, 388-393. [CrossRef]

23. Dong, M.; Anda, R.F.; Felitti, V.J.; Williamson, D.F.; Dube, S.R.; Brown, D.W.; Giles, W.H. Childhood residential mobility and multiple health risks during adolescence and adulthood: The hidden role of adverse childhood experiences. Arch. Pediatr. Adolesc. Med. 2005, 159, 1104-1110. [CrossRef] [PubMed]

24. Kaufman, J.S.; Cooper, R.S.; McGee, D.L. Socioeconomic status and health in blacks and whites: The problem of residual confounding and the resiliency of race. Epidemiology 1997, 8, 621-628. [CrossRef] [PubMed]

25. Assari, S.; Boyce, S.; Bazargan, M.; Caldwell, C.H. A Dream Deferred: African American Women's Diminished Socioeconomic Returns of Postponing Childbearing from Teenage to Adulthood. Reprod. Med. 2020, 1, 62. [CrossRef]

26. Roney, J.R. The role of sex hormones in the initiation of human mating relationships. In The Endocrinology of Social Relationships; Gray, P.B., Ellison, P.T., Eds.; Harvard University Press: Cambridge, MA, USA, 2009; pp. 246-269.

27. Smith, C.; Strohschein, L.; Crosnoe, R. Family Histories and Teen Pregnancy in the United States and Canada. J. Marriage Fam. 2018, 80, 1244-1258. [CrossRef]

28. Garwood, S.K.; Gerassi, L.; Jonson-Reid, M.; Plax, K.; Drake, B. More Than Poverty: The Effect of Child Abuse and Neglect on Teen Pregnancy Risk. J. Adolesc. Health 2015, 57, 164-168. [CrossRef] 
29. Hillemeier, M.M.; Geronimus, A.T.; Bound, S.J. Widening Black/White mortality differentials among US children during the 1980s. Ethn. Dis. 2001, 11, 469-483.

30. Geronimus, A.T. The weathering hypothesis and the health of African-American women and infants: Evidence and speculations. Ethn. Dis. 1992, 2, 207-221.

31. Nandi, P.; Kramer, M.; Kottke, M. Changing disparities in teen birth rates and repeat birth rates in Georgia: Implications for teen pregnancy prevention. Contraception 2019, 99, 175-178. [CrossRef]

32. Winters, L.I.; Winters, P.C. Black teenage pregnancy: A dynamic social problem. SAGE Open 2012, 2, 2158244012436563. [CrossRef]

33. Geronimus, A.T. Black/white differences in the relationship of maternal age to birthweight: A population-based test of the weathering hypothesis. Soc. Sci. Med. 1996, 42, 589-597. [CrossRef]

34. Young, T.; Turner, J.; Denny, G.; Young, M. Examining external and internal poverty as antecedents of teen pregnancy. Am. J. Health Behav. 2004, 28, 361-373. [CrossRef] [PubMed]

35. Cockey, C.D. Preventing teen pregnancy. It's time to stop kidding around. AWHONN Lifelines 1997, 1, 32-40. [CrossRef] [PubMed]

36. Caldas, S.J. Teen pregnancy. Why it remains a serious social, economic, and educational problem in the US. Phi Delta Kappan 1994, 75, 402-406. [PubMed]

37. Alcohol Research: Current Reviews Editorial Staff. NIH's Adolescent Brain Cognitive Development (ABCD) Study. Alcohol Res. 2018, 39, 97.

38. Bjork, J.M.; Straub, L.K.; Provost, R.G.; Neale, M.C. The ABCD study of neurodevelopment: Identifying neurocircuit targets for prevention and treatment of adolescent substance abuse. Curr. Treat. Options Psychiatry 2017, 4, 196-209. [CrossRef]

39. Casey, B.J.; Cannonier, T.; Conley, M.I.; Cohen, A.O.; Barch, D.M.; Heitzeg, M.M.; Soules, M.E.; Teslovich, T.; Dellarco, D.V.; Garavan, H.; et al. The Adolescent Brain Cognitive Development (ABCD) study: Imaging acquisition across 21 sites. Dev. Cogn. Neurosci. 2018, 32, 43-54. [CrossRef]

40. Ewing, S.W.F.; Bjork, J.M.; Luciana, M. Implications of the ABCD study for developmental neuroscience. Dev. Cogn. Neurosci. 2018, 32, 161-164. [CrossRef]

41. Ewing, S.W.F.; Chang, L.; Cottler, L.B.; Tapert, S.F.; Dowling, G.J.; Brown, S.A. Approaching Retention within the ABCD Study. Dev. Cogn. Neurosci. 2018, 32, 130-137. [CrossRef]

42. Garavan, H.; Bartsch, H.; Conway, K.; Decastro, A.; Goldstein, R.Z.; Heeringa, S.; Jernigan, T.; Potter, A.; Thompson, W.; Zahs, D. Recruiting the ABCD sample: Design considerations and procedures. Dev. Cogn. Neurosci. 2018, 32, 16-22. [CrossRef]

43. Lisdahl, K.M.; Sher, K.J.; Conway, K.P.; Gonzalez, R.; Feldstein Ewing, S.W.; Nixon, S.J.; Tapert, S.; Bartsch, H.; Goldstein, R.Z.; Heitzeg, M. Adolescent brain cognitive development (ABCD) study: Overview of substance use assessment methods. Dev. Cogn. Neurosci. 2018, 32, 80-96. [CrossRef]

44. Uban, K.A.; Horton, M.K.; Jacobus, J.; Heyser, C.; Thompson, W.K.; Tapert, S.F.; Madden, P.A.F.; Sowell, E.R.; Adolescent Brain Cognitive Development Study. Biospecimens and the ABCD study: Rationale, methods of collection, measurement and early data. Dev. Cogn. Neurosci. 2018, 32, 97-106. [CrossRef] [PubMed]

45. Volkow, N.D.; Koob, G.F.; Croyle, R.T.; Bianchi, D.W.; Gordon, J.A.; Koroshetz, W.J.; Perez-Stable, E.J.; Riley, W.T.; Bloch, M.H.; Conway, K.; et al. The conception of the ABCD study: From substance use to a broad NIH collaboration. Dev. Cogn. Neurosci. 2018, 32, 4-7. [CrossRef] [PubMed]

46. Assari, S.; Smith, J.; Mistry, R.; Farokhnia, M.; Bazargan, M. Substance Use among Economically Disadvantaged African American Older Adults; Objective and Subjective Socioeconomic Status. Int. J. Environ. Res. Public Health 2019, 16, 1826. [CrossRef]

47. Chen, E.; Paterson, L.Q. Neighborhood, family, and subjective socioeconomic status: How do they relate to adolescent health? Health Psychol. 2006, 25, 704-714. [CrossRef]

48. Moon, C. Subjective economic status, sex role attitudes, fertility, and mother's work. Ingu. Pogon. Nonjip. 1987, 7, 177-196. [PubMed]

49. Assari, S.; Preiser, B.; Lankarani, M.M.; Caldwell, C.H. Subjective Socioeconomic Status Moderates the Association between Discrimination and Depression in African American Youth. Brain Sci. 2018, 8, 71. [CrossRef] 
50. Boe, T.; Petrie, K.J.; Sivertsen, B.; Hysing, M. Interplay of subjective and objective economic wellbeing on the mental health of Norwegian adolescents. SSM Popul. Health 2019, 9, 100471. [CrossRef]

51. Wright, C.E.; Steptoe, A. Subjective socioeconomic position, gender and cortisol responses to waking in an elderly population. Psychoneuroendocrinology 2005, 30, 582-590. [CrossRef]

52. Ye, Z.; Wen, M.; Wang, W.; Lin, D. Subjective family socioeconomic status, school social capital, and positive youth development among young adolescents in China: A multiple mediation model. Int. J. Psychol. 2020, 55, 173-181. [CrossRef]

53. Ursache, A.; Noble, K.G.; Blair, C. Socioeconomic Status, Subjective Social Status, and Perceived Stress: Associations with Stress Physiology and Executive Functioning. Behav. Med. 2015, 41, 145-154. [CrossRef]

54. Senn, T.E.; Walsh, J.L.; Carey, M.P. The mediating roles of perceived stress and health behaviors in the relation between objective, subjective, and neighborhood socioeconomic status and perceived health. Ann. Behav. Med. 2014, 48, 215-224. [CrossRef] [PubMed]

55. Manuck, S.B.; Phillips, J.E.; Gianaros, P.J.; Flory, J.D.; Muldoon, M.F. Subjective socioeconomic status and presence of the metabolic syndrome in midlife community volunteers. Psychosom. Med. 2010, 72, 35-45. [CrossRef] [PubMed]

56. Mohammed, M.; AL-Habori, M.; Abdullateef, A.; Saif-Ali, R. Impact of metabolic syndrome factors on testosterone and SHBG in type 2 diabetes mellitus and metabolic syndrome. J. Diabetes Res. 2018, 2018. [CrossRef] [PubMed]

57. Hu, T.-Y.; Chen, Y.C.; Lin, P.; Shih, C.-K.; Bai, C.-H.; Yuan, K.-C.; Lee, S.-Y.; Chang, J.-S. Testosterone-associated dietary pattern predicts low testosterone levels and hypogonadism. Nutrients 2018, 10, 1786. [CrossRef]

58. Mira-Escolano, M.; Mendiola, J.; Mínguez-Alarcón, L.; Melgarejo, M.; Cutillas-Tolín, A.; Roca, M.; López-Espín, J.; Noguera-Velasco, J.; Torres-Cantero, A. Longer anogenital distance is associated with higher testosterone levels in women: A cross-sectional study. BJOG Int. J. Obstet. Gynaecol. 2014, 121, 1359-1364. [CrossRef]

59. Wells, C.C.; Riazi, S.; Mankhey, R.W.; Bhatti, F.; Ecelbarger, C.; Maric, C. Diabetic nephropathy is associated with decreasedcirculating estradiol levels and imbalance in the expression of renal estrogen receptors. Gend. Med. 2005, 2, 227-237. [CrossRef]

60. Albertsson-Wikland, K.; Rosberg, S.; Lannering, B.; Dunkel, L.; Selstam, G.; Norjavaara, E. Twenty-four-hour profiles of luteinizing hormone, follicle-stimulating hormone, testosterone, and estradiol levels: A semilongitudinal study throughout puberty in healthy boys. J. Clin. Endocrinol. Metab. 1997, 82, 541-549.

61. Krause, M.R.; Serlin, R.C.; Ward, S.E.; Rony, R.Y.Z.; Ezenwa, M.O.; Naab, F. Testing mediation in nursing research: Beyond Baron and Kenny. Nurs. Res. 2010, 59, 288. [CrossRef]

62. Pardo, A.; Román, M. Reflections on the Baron and Kenny model of statistical mediation. Anales de Psicol. 2013, 29, 614-623.

63. Baron, R.M.; Kenny, D.A. The moderator-mediator variable distinction in social psychological research: Conceptual, strategic, and statistical considerations. J. Personal. Soc. Psychol. 1986, 51, 1173. [CrossRef]

64. Talashek, M.L.; Alba, M.L.; Patel, A. Untangling the health disparities of teen pregnancy. J. Spec. Pediatr. Nurs. 2006, 11, 14-27. [CrossRef] [PubMed]

65. Pearl, M.; Braveman, P.; Abrams, B. The relationship of neighborhood socioeconomic characteristics to birthweight among 5 ethnic groups in California. Am. J. Public Health 2001, 91, 1808-1814. [CrossRef] [PubMed]

66. Kirby, D. Emerging answers: Research findings on programs to reduce teen pregnancy (summary). Am. J. Health Educ. 2001, 32, 348-355. [CrossRef]

67. Stanger-Hall, K.F.; Hall, D.W. Abstinence-only education and teen pregnancy rates: Why we need comprehensive sex education in the US. PLoS ONE 2011, 6, e24658. [CrossRef]

68. Assari, S. Unequal Gain of Equal Resources across Racial Groups. Int. J. Health Policy Manag. 2018, 7, 1-9. [CrossRef]

69. Bailey, Z.D.; Krieger, N.; Agénor, M.; Graves, J.; Linos, N.; Bassett, M.T. Structural racism and health inequities in the USA: Evidence and interventions. Lancet 2017, 389, 1453-1463. [CrossRef]

70. Boyd, R.W. Police violence and the built harm of structural racism. Lancet 2018, 392, 258-259. [CrossRef]

71. Gee, G.C.; Ford, C.L. STRUCTURAL RACISM AND HEALTH INEQUITIES: Old Issues, New Directions. Du Bois Rev. 2011, 8, 115-132. [CrossRef] 
72. Hardaway, C.R.; McLoyd, V.C. Escaping poverty and securing middle class status: How race and socioeconomic status shape mobility prospects for African Americans during the transition to adulthood. J. Youth Adolesc. 2009, 38, 242-256. [CrossRef]

73. Jee-Lyn Garcia, J.; Sharif, M.Z. Black Lives Matter: A Commentary on Racism and Public Health. Am. J. Public Health 2015, 105, e27-e30. [CrossRef]

74. Jones, A. Segregation and cardiovascular illness: The role of individual and metropolitan socioeconomic status. Health Place 2013, 22, 56-67. [CrossRef] [PubMed]

75. McCluney, C.L.; Schmitz, L.L.; Hicken, M.T.; Sonnega, A. Structural racism in the workplace: Does perception matter for health inequalities? Soc. Sci. Med. 2018, 199, 106-114. [CrossRef] [PubMed]

76. McFarland, M.J.; Taylor, J.; McFarland, C.A.S.; Friedman, K.L. Perceived Unfair Treatment by Police, Race, and Telomere Length: A Nashville Community-based Sample of Black and White Men. J. Health Soc. Behav. 2018, 59, 585-600. [CrossRef] [PubMed]

77. Trinkner, R.; Kerrison, E.M.; Goff, P.A. The force of fear: Police stereotype threat, self-legitimacy, and support for excessive force. Law Hum. Behav. 2019, 43, 421-435. [CrossRef]

78. Viruell-Fuentes, E.A.; Miranda, P.Y.; Abdulrahim, S. More than culture: Structural racism, intersectionality theory, and immigrant health. Soc. Sci. Med. 2012, 75, 2099-2106. [CrossRef]

79. Beydoun, H.A.; Sicignano, N.; Beydoun, M.A.; Bocca, S.; Stadtmauer, L.; Oehninger, S. Pubertal development of the first cohort of young adults conceived by in vitro fertilization in the United States. Fertil. Steril. 2011, 95, 528-533. [CrossRef]

80. Deardorff, J.; Gonzales, N.A.; Christopher, F.S.; Roosa, M.W.; Millsap, R.E. Early puberty and adolescent pregnancy: The influence of alcohol use. Pediatrics 2005, 116, 1451-1456. [CrossRef]

81. Miller, B.C.; Norton, M.C.; Fan, X.; Christopherson, C.R. Pubertal development, parental communication, and sexual values in relation to adolescent sexual behaviors. J. Early Adolesc. 1998, 18, 27-52. [CrossRef]

82. De Genna, N.M.; Larkby, C.; Cornelius, M.D. Pubertal timing and early sexual intercourse in the offspring of teenage mothers. J. Youth Adolesc. 2011, 40, 1315-1328. [CrossRef]

83. Gibb, S.J.; Fergusson, D.M.; Horwood, L.J.; Boden, J.M. Early motherhood and long-term economic outcomes: Findings from a 30-year longitudinal study. J. Res. Adolesc. 2015, 25, 163-172. [CrossRef]

84. Leung, M.Y.M.; Groes, F.; Santaeulalia-Llopis, R. The relationship between age at first birth and mother's lifetime earnings: Evidence from Danish data. PLoS ONE 2016, 11, e0146989. [CrossRef] [PubMed]

85. Hillis, S.D.; Anda, R.F.; Dube, S.R.; Felitti, V.J.; Marchbanks, P.A.; Marks, J.S. The association between adverse childhood experiences and adolescent pregnancy, long-term psychosocial consequences, and fetal death. Pediatrics 2004, 113, 320-327. [CrossRef] [PubMed]

86. Stephens, M.A.C.; Mahon, P.B.; McCaul, M.E.; Wand, G.S. Hypothalamic-pituitary-adrenal axis response to acute psychosocial stress: Effects of biological sex and circulating sex hormones. Psychoneuroendocrinology 2016, 66, 47-55. [CrossRef] [PubMed]

87. Rogol, A.D.; Clark, P.A.; Roemmich, J.N. Growth and pubertal development in children and adolescents: Effects of diet and physical activity. Am. J. Clin. Nutr. 2000, 72, 521S-528S. [CrossRef]

88. Andersson-Ellström, A.; Forssman, L.; Milsom, I. Age of sexual debut related to life-style and reproductive health factors in a group of Swedish teenage girls. Acta Obstet. Gynecol. Scand. 1996, 75, 484-489. [CrossRef]

89. DiCenso, A.; Guyatt, G.; Willan, A.; Griffith, L. Interventions to reduce unintended pregnancies among adolescents: Systematic review of randomised controlled trials. BMJ 2002, 324, 1426. [CrossRef]

90. Shin, Y.; Rew, L. A mentoring program for the promotion of sexual health among Korean adolescents. J. Pediatric Health Care 2010, 24, 292-299. [CrossRef]

91. Haase, J.E. The adolescent resilience model as a guide to interventions. J. Pediatric Oncol. Nurs. 2004, 21, 289-299. [CrossRef]

92. Zimmerman, M.A.; Stewart, S.E.; Morrel-Samuels, S.; Franzen, S.; Reischl, T.M. Youth empowerment solutions for peaceful communities: Combining theory and practice in a community-level violence prevention curriculum. Health Promot. Pract. 2011, 12, 425-439. [CrossRef]

93. Ethier, K.; St Lawrence, J.S. The role of early, multilevel youth development programs in preventing health risk behavior in adolescents and young adults. Arch. Pediatrics Adolesc. Med. 2002, 156, 429-430. [CrossRef]

94. Brody, G.H.; Yu, T.; Chen, E.; Miller, G.E. Family-centered prevention ameliorates the association between adverse childhood experiences and prediabetes status in young black adults. Prev. Med. 2017, 100, 117-122. [CrossRef] [PubMed] 
95. Brody, G.H.; Murry, V.M.; Gerrard, M.; Gibbons, F.X.; Molgaard, V.; McNair, L.; Brown, A.C.; Wills, T.A.; Spoth, R.L.; Luo, Z. The strong African American families program: Translating research into prevention programming. Child Dev. 2004, 75, 900-917. [CrossRef] [PubMed]

96. Ross, D.P. Policy Approaches to Address the Impact of Poverty on Health. Available online: https: //secure.cihi.ca/free_products/CPHIPolicyApproaches_e.pdf (accessed on 30 July 2020).

97. Flook, L.; Fuligni, A.J. Family and school spillover in adolescents' daily lives. Child Dev. 2008, 79, $776-787$. [CrossRef] [PubMed]

(C) 2020 by the authors. Licensee MDPI, Basel, Switzerland. This article is an open access article distributed under the terms and conditions of the Creative Commons Attribution (CC BY) license (http://creativecommons.org/licenses/by/4.0/). 